\title{
Changes in neuronal activity in the cochlear nucleus as a function of classical and instrumental conditioning ${ }^{1}$
}

\author{
EDWARD S. HALAS and JAMES $V$. \\ $B E A R D S L E Y,{ }^{2}$ University of North \\ Dakota, Grand Forks, N. Dak. 58201
}

Multiple-unit neuronal responses were recorded from the cochlear nucleus of five cats during classical and instrumental conditioning. For two of the Ss, complex neuronal responses were observed during instrumental conditioning, while a simple response was observed during classical conditioning. Extinction of neuronal responses after each training procedure also differed.

Three different patterns or configurations of neuronal responses were observed in the cochlear nucleus of a cat during instrumental conditioning, as compared to only one pattern of response during classical conditioning (Halas \& Beardsley, 1969). Furthermore, the first neuronal response to appear in instrumental conditioning was essentially identical in configuration to the neuronal response in classical conditioning. These neuronal data are in agreement with behavioral data that indicate that the early phases of instrumental conditioning are similar to classical conditioning (Bitterman, 1966). The present paper examines the neuronal responses in the cochlear nucleus of five cats during classical and instrumental conditioning.

\section{METHOD}

The Ss were five adult cats with chronically implanted electrodes. The procedure for implanting an electrode in the dorsal cochlear nucleus has been described elsewhere (Buchwald, Halas, \& Schramm, 1966; Halas \& Beardsley, 1968). The multiple-unit neuronal activity was displayed on a Tektronix 565 oscilloscope and photographed with a Grass C4 camera. A modified version of the Weber \& Buchwald (1965) electronic integrator was used to count the frequency of the multiple-unit activity. The integration of the frequency count was displayed on the scope and photographed simultaneously with the neuronal activity. Pin lights mounted on the scope recorded the duration of the $\mathrm{CS}$ and US, which consisted of a $1,500-\mathrm{Hz}$ tone paired with a mild electric shock to the hindpaw of the cat. The CS lasted $1.5 \mathrm{sec}$ and the US lasted $0.5 \mathrm{sec}$. The US overlapped the last third of the CS.
The Ss were given 500 habituation trials to the tone at the rate of 39 trials per day ( 32 trials on the last day), followed by 800 trials of paired tone and shock during classical conditioning. The Ss were then given 500 extinction trials, followed by a 6-week rest period. After a second habituation of 500 trials, the Ss were given 1,000 instrumental avoidance trials. If the $S$ lifted its hindpaw during the first $1.0 \mathrm{sec}$ of the tone, shock was not given. Five hundred extinction trials followed the avoidance training. Intertrial intervals ranged randomly from 20 to $50 \mathrm{sec}$.

\section{RESULTS}

Of the five Ss, two showed systematic changes in neuronal activity during classical and instrumental conditioning, while the remaining Ss failed to develop conditioned neuronal responses. The results of one of the successfully conditioned Ss are shown in Fig. 1. During habituation and the first 34 training trials, no neuronal responses were observed (Traces A and B). On Trial 35, a slight increase in neuronal activity appeared (Trace C) that gradually increased (Trace D). This neuronal response was characterized by its relatively long latency and high amplitude (Trace D). As training progressed, the latency became longer (Trace E). This conditioned neuronal response was then extinguished (Trace F). The conditioned neuronal response appeared on $83 \%$ of the trials from Trial 34 through Trial 111, while the conditioned behavioral response appeared in $25 \%$ of the trials. From Trial 112 through Trial 800 , conditioned neuronal responses were observed $78 \%$ of the time, while conditioned behavioral responses were recorded in $68 \%$ of the trials.

No neuronal responses were observed during the first 142 trials of instrumental conditioning (Trace $\mathrm{H}$ ). Starting with Trial 143 (Trace I), a conditioned neuronal response appeared and was observed in $77 \%$ of the trials, up to Trial 250 . This response was also characterized by a long latency and high amplitude. On Trial 251, the neuronal response evolved into two components, consisting of a short-latency, low-amplitude component followed by a long-latency, high-amplitude component (Trace J). This two-component response appeared $67 \%$ of the time from Trial 251 through Trial 432, while the conditioned behavioral response was observed in $74 \%$ of the trials. The long-latency, high-amplitude component of the neuronal response had disappeared by Trial 433 (Trace K), leaving just the short-latency, low-amplitude component. From Trial 433 to Trial 1,000, this short-latency response appeared in $84 \%$ of the trials, and the behavioral response was recorded $79 \%$ of the time. The neuronal response was then extinguished (Trace L).

The conditioned neuronal response for the second $S$ was quite different in configuration. No neuronal response appeared during habituation and the first 42 trials of classical conditioning (Fig. 2; Traces A and B). But, on Trial 43, a positive onset response appeared (Trace $C$ ) that persisted for $53 \%$ of the trials, up to Trial 87. No conditioned behavioral responses were observed up to this point. A positive onset followed by a marked inhibition of neuronal activity appeared on Trial 88 (Trace D). This complex response was observed in $72 \%$ of the trials for the remainder of the acquisition trials, although there was a tendency for the response to disappear or become weaker later in training (Trace E). Conditioned behavioral responses were observed in $64 \%$ of the trials. During extinction, the onset component of the neuronal response proved to be the most difficult to extinguish (Trace F).

During instrumental conditioning, no neuronal responses were observed during the first 73 trials of acquisition (Trace $\mathrm{H}$ ). On Trial 74, a positive onset followed by a slight inhibition was observed (Trace I). This response was observed in $79 \%$ of the trials and, interestingly, resembled the neuronal response observed during classical conditioning (Trace D). While no conditioned behavioral response was recorded in the first 73 trials, behavioral responses were recorded on $42 \%$ of the trials from Trial 74 through Trial 744 . The neuronal inhibition gradually disappeared, although the onset component remained (Trace J). This response was observed $75 \%$ of the time from Trial 745 through Trial 853, while the conditioned behavioral response was recorded in $73 \%$ of the trials. As the inhibition disappeared, a marked acceleration of neuronal activity developed that followed the onset component (Trace K). The marked acceleration was observed in $65 \%$ of the trials from Trial 854 through Trial 1,000, and the conditioned behavioral response appeared in $78 \%$ of the trials. Although the behavioral response was successfully extinguished, the neuronal response did not extinguish (Trace L).

\section{DISCUSSION}

The data from the present study support the results reported by Halas \& Beardsley (1969) that the neuronal responses 


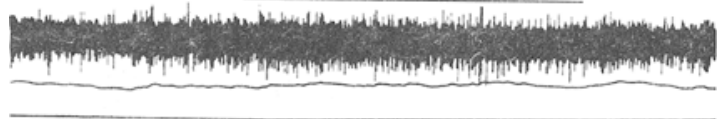

TRACE B TRAINING TRIAL 34

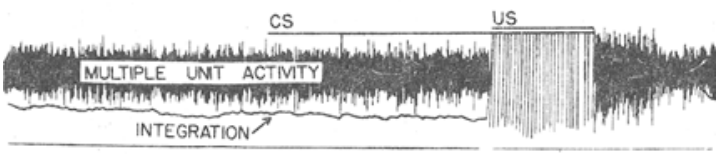

TRACE C TRIAL 35

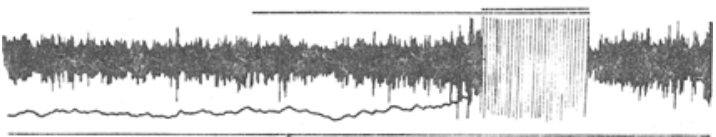

TRACE D TRIAL $\| 2$

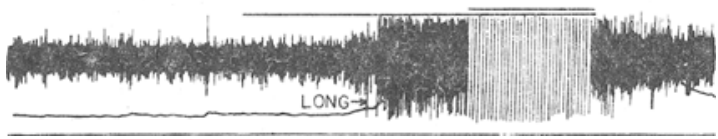

TRACE E TRIAL 800
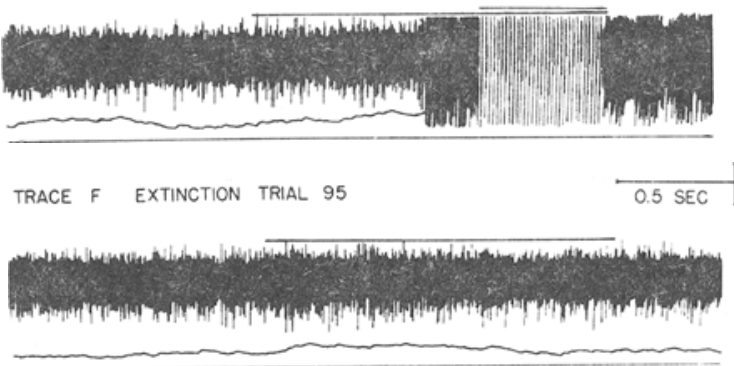

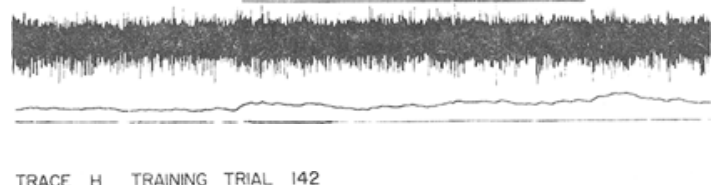

TRACE H TRAINING TRIAL 142

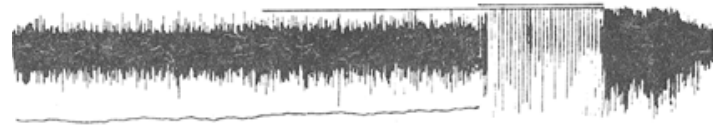

TRACE I TRIAL 143

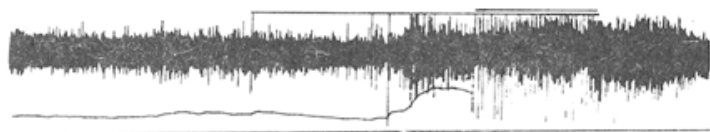

TRACE J TRIAL 251

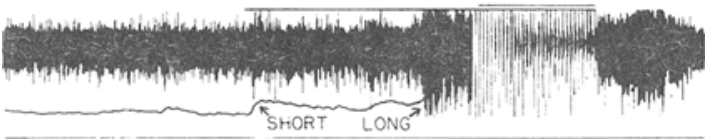

TRACE $K$ TRIAL 433

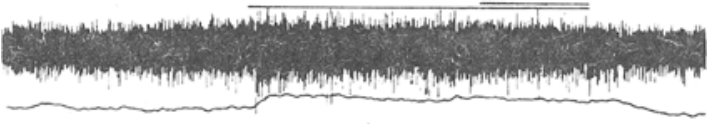

TRACE L EXTINCTION TRIAL 275

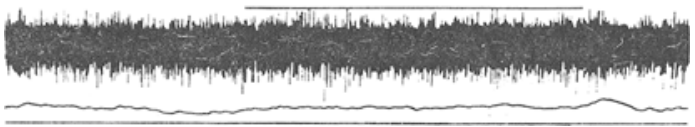

Fig. 1. A comparison of neuronal activity during classical and instrumental conditioning. Traces $D$ and $E$ show the long latency response observed in classical conditioning, while Trace I shows the same response in early instrumental conditioning. Trace $J$ shows the fully developed long-latency response as well as the beginning of the short-latency response. The large vertical lines during the US period are due to shock artifact.

observed during instrumental conditioning are more complex than the neuronal responses in classical conditioning. Furthermore, the first neuronal response to appear during instrumental conditioning was very similar in configuration to the response observed in classical conditioning; this suggests that the early phases of instrumental conditioning do involve a classical conditioning phenomenon. However, the configuration of the responses during instrumental conditioning differed among the cats. The differences between cats could be due to variation of the electrode placement in the dorsal cochlear nucleus or they may be due to some other, unknown factor.

These changes in the cochlear nucleus during conditioning support the earlier paper (Halas \& Beardsley, 1970) that subcortical auditory nuclei have not only a role in the transmission of sensory information but are also a part of the neural complex that mediates learning. Previous research (Halas, Beardsley, \& Sandlie, in press) has suggested that the neural coupling of the CS and the US first occurs within the reticular formation. The present research suggests that the long-term process of conditioning continues in the primary sensory pathway of the CS.

One of the unexpected results was the difficulty in extinguishing the neuronal response after instrumental conditioning. One of the two Ss in the present study and the cat reported earlier (Halas \& Beardsley, 1969) showed this phenomenon. The conditioned behavioral responses, by comparison, extinguished within 100 trials. As yet, there is no reasonable explanation other than to suggest that the significance of the CS is not forgotten even though the conditioned behavioral response is not elicited. This assumption is supported by the findings of Solomon \& Wynne (1953), who observed that avoidance conditioning was very difficult to extinguish if the avoidance reaction took place within $1.5 \mathrm{sec}$ of the CS onset. These investigators reasoned that the latencies of the visceral responses associated with fear of the $\mathrm{CS}$ were so long that they did not occur in the presence of the CS and therefore would be very difficult to extinguish. In the present study, the overt behavioral response was successfully extinguished, but the short duration of the $\mathrm{CS}$, according to the 

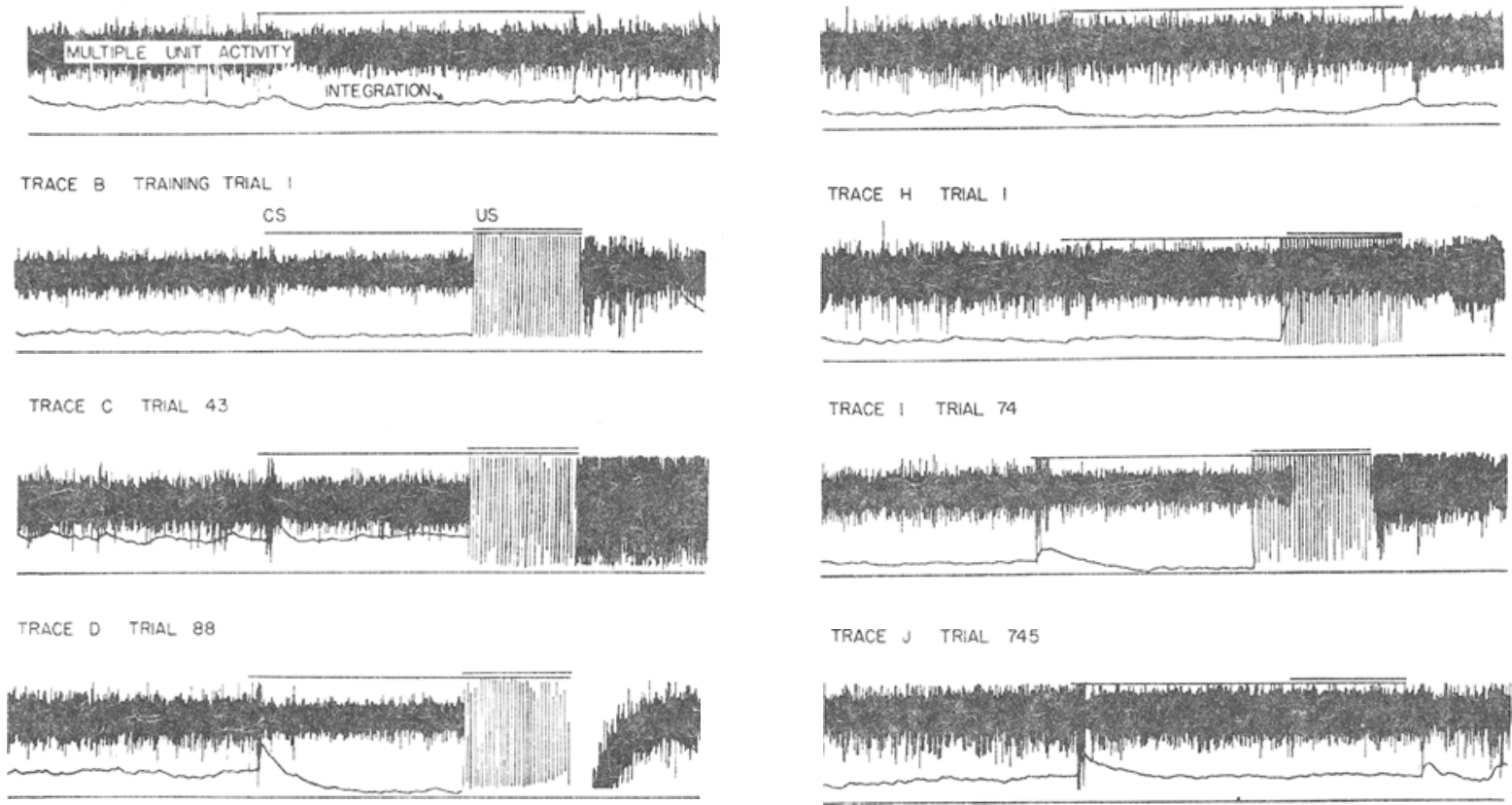

TRACE E TRIAL 629

TRACE $K$ TRIAL. 854
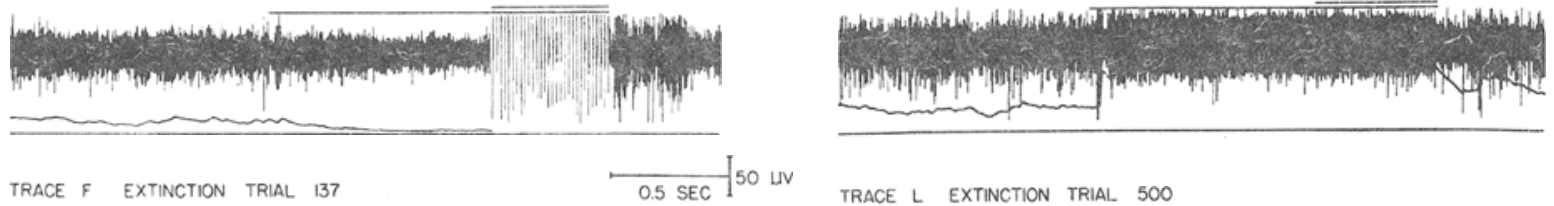

TRACE L EXTINCTION TRIAL 500
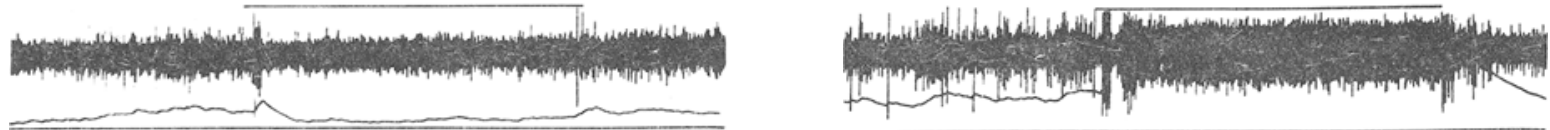

Fig. 2. Trace $\mathrm{C}$ shows the first onset response, which then is followed by inhibition, as shown in Trace $\mathrm{D}$. Trace I shows the same response during early instrumental conditioning. The inhibition has disappeared by Trace $J$, and later an acceleration of neuronal activity developed, as shown in Trace $K$. Trace $L$ illustrates the resistance to extinction of this response.

Solomon-Wynne thesis, would not allow the fear reactions to be readily extinguished. These findings suggest that the neural network mediating a conditioned response remains at least partially intact even though the conditioned behavioral response has been extinguished. The ease of reestablishing most conditioned behavioral responses after extinction supports this assumption.

\section{REFERENCES}

BITTERMAN, M. E. Animal learning. In J. B. Sidowski (Ed.), Experimental methods and instrumentation in psychology. New York: MoGraw-Hill, 1966. Pp. 451-484.

BUCHWALD, J. S., HALAS, E. S., \&

SCHRAMM, S. Changes in cortical and subcortical unit activity during conditioning in chronic cats. Physiology \& Behavior, 1966, 1, 11-22.

HALAS, E. S., \& BEARDSLEY, J. V. Specificity of multiple unit activity in the sensory nuclei of cats. Physiology \& Behavior, 1968, 3, 275-279.

HALAS, E. S., \& BEARDSLEY, J. V. Different responses in the cochlear nucleus of a cat during classical and instrumental conditioning. Psychonomic Science, 1969, 17, 141-142.

HALAS, E. S., \& BEARDSLEY, J. V. A comparison of conditioned and unconditioned neuronal responses in the inferior colliculus of cats. Psychonomic Science, 1970, 18, 29-30.

HALAS, E. S., BEARDSLEY, J. V., \& SANDLIE, M. E. Conditioned neuronal responses at various levels in conditioning paradigms. Electroencephalography \& Clinical Neurophysiology, in press.
SOLOMON, R, L., \& WYNNE, L. C. Traumatic avoidance learning: Acquisition in normal dogs. Psychological Monographs, 1953, 67, No. 354, 19.

WEBER, D. S., \& BUCHWALD, J. S. A technique for recording and integrating multiple-unit activity simultaneously with the EEG in chronic animals. Electroencephalography \& Clinical Neurophysiology, 1965, 19, 190-192.

\section{NOTES}

1. This research was supported by NSF Grant GB-7265 and by NIMH Grants MH-11150 and $\mathrm{MH}-14375$.

2. Present address: Department of Neurology, University of Wisconsin Medical Center, Madison, Wis. 53706 . 